Article

\title{
Isolation and Characterization of an Antibacterial Peptide Fraction from the Pepsin Hydrolysate of Half-Fin Anchovy (Setipinna taty)
}

\section{Ru Song ${ }^{1,2, *}$, Rong-Bian Wei ${ }^{1}$, Hong-Yu Luo ${ }^{1}$ and Dong-Feng Wang ${ }^{2}$}

1 Department of Food Science, College of Food Science and Pharmacy, Zhejiang Ocean University, Zhoushan 316000, China; E-Mails: windswingcn@yahoo.com.cn (R.-B.W.); hongyuluo68@yahoo.cn (H.-Y.L.)

2 College of Food Science and Engineering, Ocean University of China, Qingdao 266003, China; E-Mail: wangfengd60@yahoo.cn

* Author to whom correspondence should be addressed; E-Mail: rusong@zjou.edu.cn; Tel./Fax: +86-580-255-4781.

Received: 2 December 2011; in revised form: 1 March 2012 / Accepted: 5 March 2012 / Published: 9 March 2012

\begin{abstract}
Enzymatic proteolysis of food proteins is considered a promising method to generate antibacterial peptides. The objective of the present study was to isolate and characterize peptide fraction from the pepsin hydrolysate of half-fin anchovy (Setipinna taty) with antibacterial activity against Escherichia coli. The most active peptide fraction HAHp2-3-I was isolated by a series of chromatographic methods, including Sephadex G-25 chromatography, reverse high-performance liquid chromatography (RP-HPLC) and Source 5RPC ST. Peptides identification of HAHp2-3-I was carried out using UPLC-LTQ-Orbitrap mass spectrometer. HAHp2-3-I contained five cationic peptides (MLTTPPHAKYVLQW, SHAATKAPPKNGNY, PTAGVANALQHA, QLGTHSAQPVPF and VNVDERWRKL) and three anionic peptides (LATVSVGAVELCY, NPEFLASGDHLDNLQ and PEVVYECLHW). Prediction of peptide secondary structure indicated that these anionic peptides should have extended strand and random coil structures, whereas cationic peptides PTAGVANALQHA and VNVDERWRKL could form alpha helixes. In addition, results of scanning electron microscopy (SEM) revealed that treatment by HAHp2-3-I could cause the morphological changes of $E$. coli and destruction of the cell integrity via irreversible membrane damage. The results could provide information for investigating the antibacterial model of antibacterial peptides derived from fish protein hydrolysates.
\end{abstract}


Keywords: half-fin anchovy pepsin hydrolysate; isolation; peptide sequence; secondary structure prediction; membrane disruption

\section{Introduction}

In the last two decades, the increase of bacterial resistance to commercial antibiotics and the increased restriction on the use of chemical preservatives in foods have greatly stimulated the search for novel alternative natural antimicrobial agents that possess a broad spectrum of antibiotic activity. Since the first antimicrobial peptide was identified from the cecropia moth (Hyatophora cecropia) [1], a variety of antimicrobial peptides (AMPs) have been found with numerous origins, such as plants, animals and microorganisms [2-4]. Proteolytic digests of proteins also generate AMPs, in fact, many AMPs including casecidins, isracidin and casocidin-I were initially isolated from bovine casein hydrolysates [5-7]. Although AMPs are mainly generated from milk source protein hydrolysates, other types of proteins, after hydrolysis, have the potential of releasing novel AMPs or enhancing bioactivities, compared with their intact forms [8-10]. Therefore, digestion of proteins to release AMPs might open a new way to produce antimicrobial ingredients in large scale [11].

Fish possess a strong innate immune system, which acts as the first line of defense against pathogen infections [12]. Fish AMPs and their possible applications are reported in recent papers [4,13]. These fish origin AMPs have positive charge and amphipathic characteristics like other AMPs from terrestrial animals [4]. Researchers have focused on preparation of fish AMPs from fish secretes, organ extractions, or transgenic expression [14-16]. However, there are few investigations on AMPs from fish hydrolysates. Half-fin anchovy (Setipinna taty) is an under-utilized marine fish found in the coastal waters of China. In our previous study, we found that the pepsin hydrolysate of half-fin anchovy (HAHp) possessed antibacterial activity against Gram-positive and Gram-negative bacteria [17]. The main objective of this study is to isolate and characterize the antibacterial peptide fraction from HAHp. Moreover, we discuss the possible antibacterial model, aiming at providing information for further investigation of antibacterial mechanism of fish source AMPs derived from fish hydrolysates.

\section{Results and Discussion}

\subsection{Isolation and Identification of Antibacterial Fraction from $\mathrm{HAHp}$}

\subsubsection{Gel Permeation Chromatography}

HAHp was first separated into four chromatographic peaks by Sephadex G-25 chromatography (Figure 1a). The fraction HAHp2 (represented in peak 2) showed the strongest activity against E. coli among all fractions attained. Bioassay guided chromatography for further separation of the fraction HAHp2 provided three additional peaks, which were eluted with deionized water on the Sephadex G-25 column. Peak 2-3 (named as HAHp2-3) demonstrated antibacterial activity on E. coli (Figure 1b). Peptides with net charges or hydrophobic characteristics are easily absorbed to the gel when deionized water is used as eluent, resulting in delayed peaks. 
Figure 1. Chromatogram profiles and antibacterial activity of fractions isolated by Sephadex G-25 gel. (a) Eluted with $50 \mathrm{mM}$ sodium phosphate buffer in $0.15 \mathrm{~mol} / \mathrm{L} \mathrm{NaCl}$ (pH 5.8) at a flow rate of $1.0 \mathrm{~mL} / \mathrm{min}$. (b) Eluted with deionized water at a flow rate of $0.5 \mathrm{~mL} / \mathrm{min}$. Numbers beside the wells were corresponding to the peak numbers in chromatographic diagram.
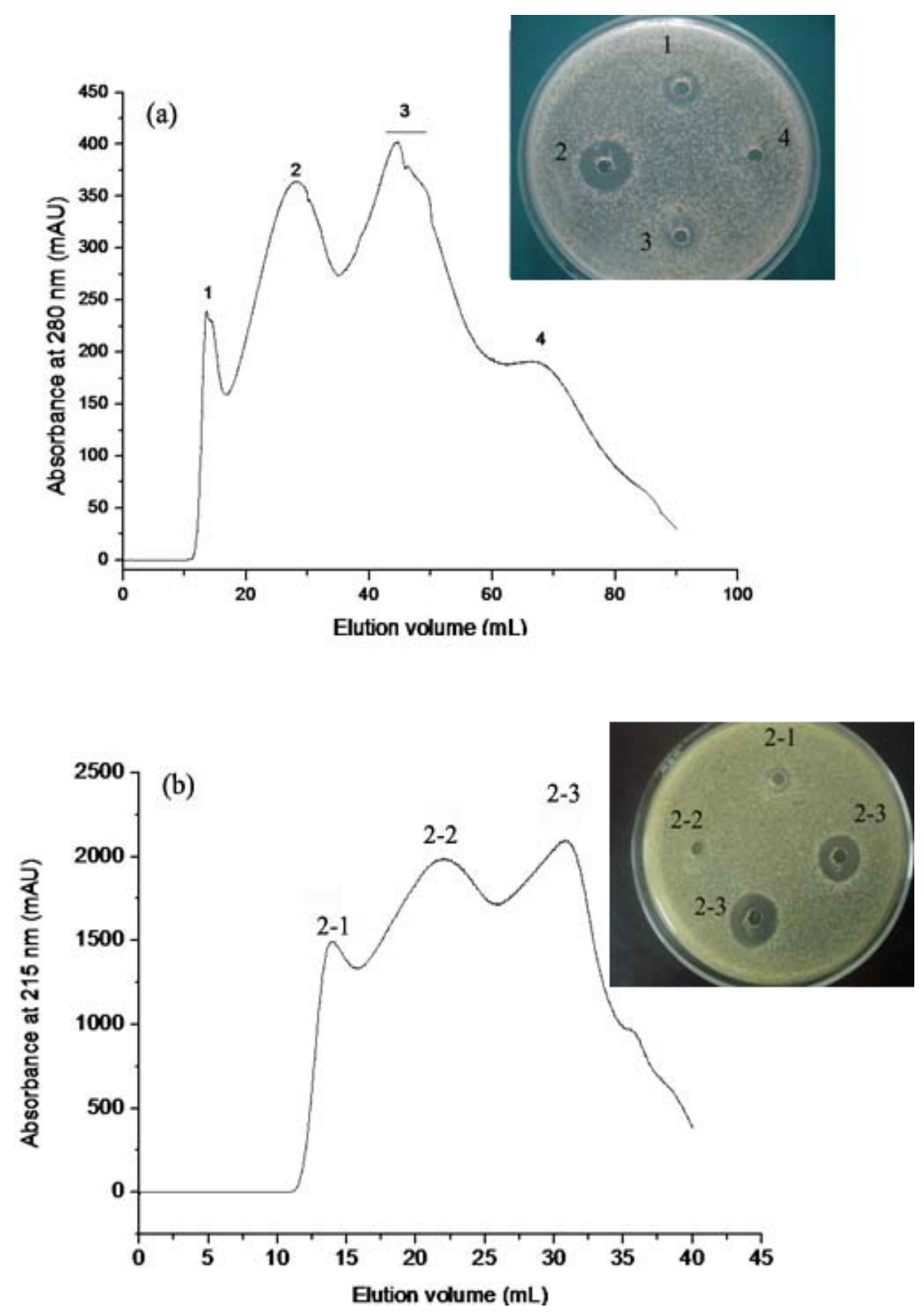

Highly cationic antibacterial peptides are easily attracted to the anionic charges that exist on the outer envelope of the cell wall of Gram-negative bacteria. Furthermore, the hydrophobic properties of peptides enable them to perturb the cell membrane integrity or translocate into the cytoplasm [18-20]. In this sense, the strongest antibacterial activity of HAHp2-3 of all three peaks (the others are HAHp2-1 and HAHp2-2) may be due to its net charges or hydrophobic properties. Our following analysis of the physicochemical properties of peptides confirmed this speculation. 


\subsubsection{RP-HPLC and Source 5RPC ST purification}

HAHp2-3 was further separated into several peaks by preparative RP-HPLC. The resulting peak 1 displayed the strongest antibacterial activity and was named as HAHp2-3-I (Figure 2). It was sub-fractionated into two more peaks (peak a and peak b) when analyzed with a Source 5RPC ST analytical HPLC column (Figure 3). Both peaks showed antibacterial activity. Therefore, we loaded HAHp2-3-I onto UPLC-LTQ-Orbitrap mass spectrometer for further purification and identification, aiming at revealing all peptide sequences in a simple and economical way.

Figure 2. Fractionation and antibacterial activity of HAHp2-3 using preparative RP-HPLC. Numbers beside the wells were consistent with the peak numbers in RP-HPLC profile.

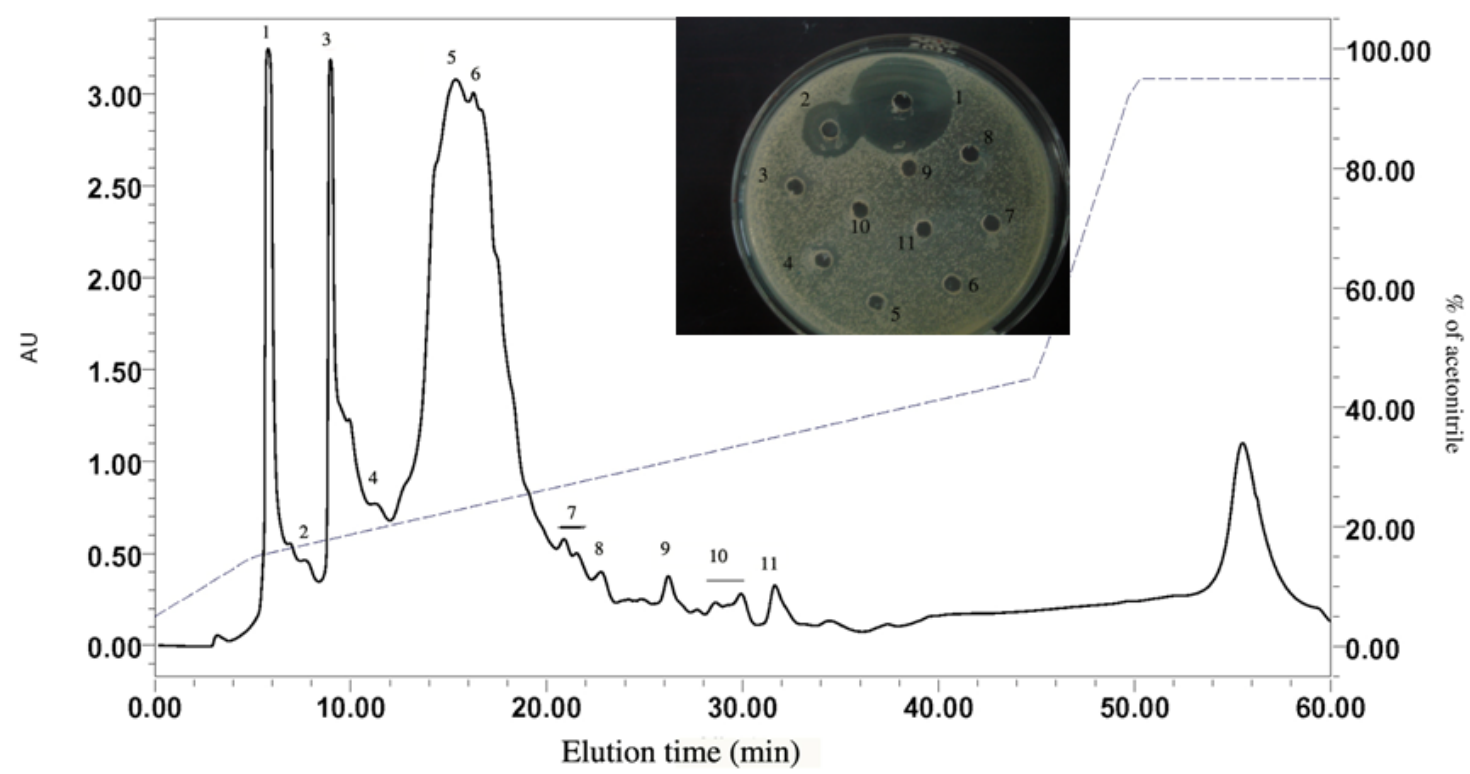

Figure 3. Chromatogram profile and antibacterial activity of HAHp2-3-I analyzed by Source 5RPC ST column. Numbers beside the wells represented the peak numbers in the chromatogram profile.

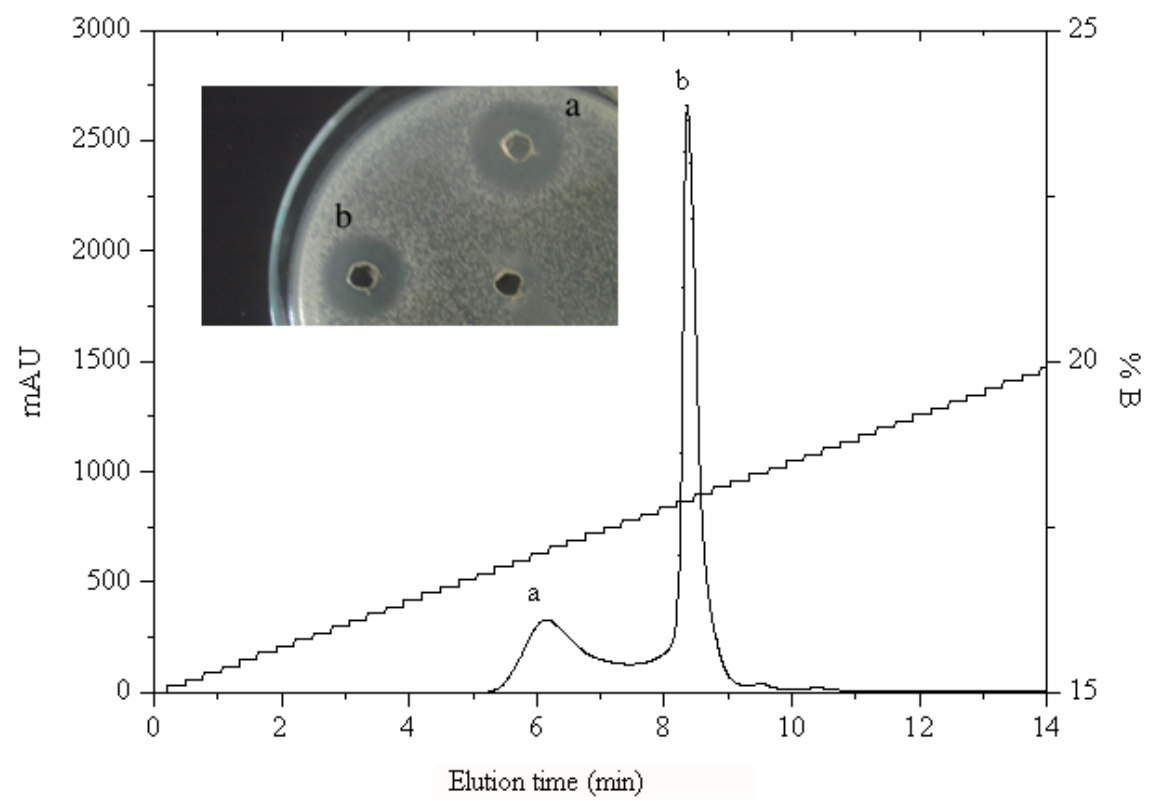




\subsection{Peptide Sequence Analysis and Physicochemical Properties}

HAHp2-3-I was composed of more than ten peptides (Figure 4). Ten peptide sequences were selectively analyzed for those with eluting time of 15.92, 18.24, 19.21, 19.95, 20.52, 21.45, 23.24, 23.86, 33.55 and $34.48 \mathrm{~min}$, respectively (Table 1). The molecular weights of these peptides ranged from 1,100 to 1,700 Da. The observed masses were all less than 18 Da compared to their calculated masses, which may be due to the loss of one water molecule. Eight peptides with charge were identified, including five cationic ones: MLTTPPHAKYVLQW (HAHp-cationic1), SHAATKAPPKN GNY (HAHp-cationic2), PTAGVANALQHA (HAHp-cationic3), QLGTHSAQPVPF (HAHp-cationic4), and VNVDERWRKL (HAHp-cationic5) and three anionic ones: LATVSVGAVELCY (HAHp-anionic1), NPEFLASGDHLDNLQ (HAHp-anionic2), and PEVVYECLHW (HAHp-anionic3). HAHp-catoinic2 possessed the highest cationic charges $(+3)$, whereas its hydrophobic ratio $(21 \%)$ was the lowest among the five cationic peptides. In contrast, HAHp-cationic3 had the highest hydrophobic ratio $(50 \%)$ and the lowest cationic charges $(+1)$. HAHp-catoinic1 had intermediate net charges $(+2)$ and hydrophobicity ratio $(42 \%)$. The antibacterial activity of cationic peptides can be modulated through modification of net charge or the ratio of hydrophobicity [21,22]. Nevertheless, the exposed basic residues of anionic peptides are not essential for their antibacterial activities. For example, the antibacterial activity of anionic peptides, Cn-AMP2 (TESYFVFSVGM) and Cn-AMP3 (YCSYTMEA) are related with their hydrophobic amino acid residues [19]. In this study, HAHp-anionic1 and HAHp-anionic3 displayed higher hydrophobic percentages than other peptides. Results in Table 1 indicate that the antibacterial activity of HAHp2-3-I may be due to its cationic and, or hydrophobic characteristics.

Figure 4. UPLC chromatogram profile (Michrom $\mathrm{C}_{18}, 0.1 \times 150 \mathrm{~mm}$ ) of HAHp2-3-I. 0-5 min, 5\% solvent B; 5-12 min, 5-8\% solvent B; 12-22 min, 8-13\% solvent B; $22-42$ min, $13-30 \%$ solvent $\mathrm{B}$.

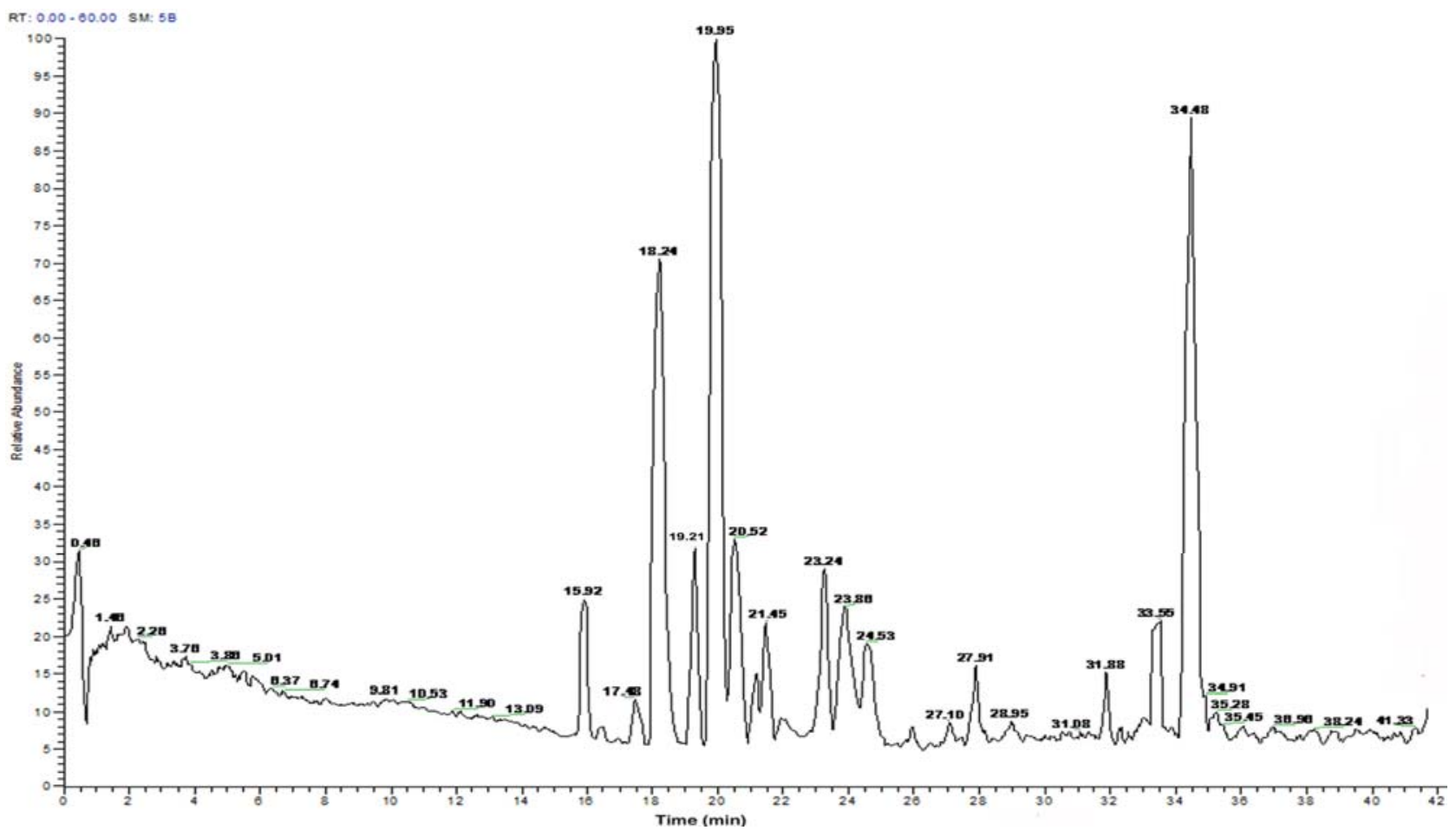


Table 1. Amino acid sequences of selected peptides in fraction HAHp2-3-I.

\begin{tabular}{ccccc}
\hline $\begin{array}{c}\text { Time } \\
(\mathbf{m i n})\end{array}$ & Amino acid sequence & $\begin{array}{c}\text { Calculated mass } \\
\text { /observed mass }\end{array}$ & $\begin{array}{c}\text { Net } \\
\text { charge }\end{array}$ & $\begin{array}{c}\text { Hydrophobic ratio }{ }^{\mathbf{b}} \\
\text { (\%) }\end{array}$ \\
\hline 15.92 & MLTTPPHAKYVLQW & $1685.0 / 1665.92$ & +2 & 42 \\
18.24 & LRSKAAAPAEQYE & $1433.5 / 1414.78$ & 0 & 38 \\
19.21 & TPGALLEHPTL & $1148.3 / 1129.60$ & 0 & 36 \\
19.95 & SHAATKAPPKNGNY & $1455.5 / 1436.91$ & +3 & 21 \\
20.52 & LATVSVGAVELCY & $1324.5 / 1305.73$ & -1 & 61 \\
21.45 & PTAGVANALQHA & $1149.2 / 1130.67$ & +1 & 50 \\
23.24 & QLGTHSAQPVPF & $1281.4 / 1262.62$ & +1 & 33 \\
23.86 & VNVDERWRKL & $1314.5 / 1295.65$ & +1 & 40 \\
33.55 & NPEFLASGDHLDNLQ & $1669.7 / 1650.89$ & -2 & 33 \\
34.48 & PEVVYECLHW & $1274.4 / 1255.72$ & -1 & 50 \\
\hline
\end{tabular}

${ }^{\mathrm{a}}$ Net charge was calculated based on negatively charged amino acid (E and D) and positively charged amino acid $(\mathrm{K}, \mathrm{R}$ and $\mathrm{H})$ in the peptide sequence; ${ }^{\mathrm{b}}$ Calculated the percentage of hydrophobic residues (I, V, L, F, C, M, A, W) in the peptide sequence.

\subsection{Prediction of Peptide Secondary Structure}

The ten peptides identified in fraction HAHp2-3-I all had no disulfide bridges. Peptides without disulfide bridges are in disorder when dissolved in aqueous solutions. However, when they bind to a membrane or in other hydrophobic environment, or when self-aggregation occurs, all or part of the molecule may convert to a secondary structure [23-25]. The predictions of secondary structure of these charged peptides derived from HAHp2-3-I are listed in Table 2.

Table 2. Secondary structure prediction of charged peptides in HAHp2-3-I.

\begin{tabular}{|c|c|c|}
\hline Peptides & Amino acid sequence $^{\mathrm{a}}$ & Secondary structure $^{b}$ \\
\hline HAHp-cationic 1 & $\begin{array}{l}\text { MLTTPPHAKYVLQW } \\
\text { cсcсcсcсceeecc }\end{array}$ & Extended strand $(21.43 \%)$, random coil $(78.57 \%)$ \\
\hline HAHp-cationic2 & $\begin{array}{l}\text { SHAATKAPPKNGNY } \\
\text { cсcсcсcсc⿻cс㇒c }\end{array}$ & Random coil $(100 \%)$ \\
\hline HAHp-cationic 3 & $\begin{array}{l}\text { PTAGVANALQHA } \\
\text { cccchhhhhccc }\end{array}$ & Alpha helix (41.67\%), random coil (58.33\%) \\
\hline HAHp-cationic 4 & $\begin{array}{l}\text { QLGTHSAQPVPF } \\
\text { ccccccccccc }\end{array}$ & Random coil (100\%) \\
\hline HAHp-cationic5 & $\begin{array}{l}\text { VNVDERWRKL } \\
\text { cccchhhccc }\end{array}$ & Alpha helix $(30.00 \%)$, random coil $(70.00 \%)$ \\
\hline HAHp-anionic1 & $\begin{array}{l}\text { LATVSVGAVELCY } \\
\text { ceeeeeeeeecc }\end{array}$ & Extended strand $(76.92 \%)$, random coil $(23.08 \%)$ \\
\hline HAHp-anionic2 & 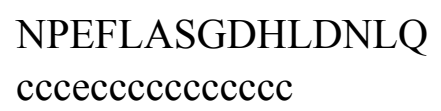 & Extended strand $(6.67 \%)$, random coil $(93.33 \%)$ \\
\hline HAHp-anionic3 & $\begin{array}{l}\text { PEVVYECLHW } \\
\text { cceeeeeecc }\end{array}$ & Extended strand $(60.00 \%)$, random coil $(40.00 \%)$ \\
\hline
\end{tabular}


Peptides HAHp-cationic3 and HAHp-cationic5 showed the capacity of forming alpha helix structures. Moreover, the percentage of alpha helix of HAHp-cationic3 (41.67\%) was obviously higher than that of HAHp-cationic5 (30.00\%). HAHp-cationic1, HAHp-cationic2 and HAHp-cationic4 lacked of alpha helixes, and they were mainly or totally composed of random coils.

As for the anionic peptides from HAHp2-3-I, they were composed of extended strand and random coil structures. Previous study showed the increased alpha helix contents for AMPs are often correlated with their stronger activities [26]. However, many AMPs which lack an alpha helix, such as indolicidin (ILPWKWPWWPWRR-NH2) and CP11CN (ILKKWPWWPWRRK-NH2) can penetrate phosphor-lipid monolayers, mediate lipid flip-flop and cause leakage of calcein across the membrane [27], whereas their secondary structures are only the random coils, as predicted by Hierarchical Neural Network tool. Our results of the prediction of peptide secondary structure shown in Table 2 are similar to that study, and concordant with the antibacterial activity exhibited by fraction HAHp2-3-I.

\subsection{Scanning Electron Microscopy (SEM)}

In the control group a normal surface of $E$. coli can be shown and without apparent cellular debris (Figure 5a). By comparison, a variety of morphological changes were visualized in the treated groups by HAHp2-3-I (Figure 5b,c). For example, the cell membrane surface in treated groups was rougher than that of the control, with pores and micelles appearing on the membrane surfaces. In addition, membrane disruption was observed in some cells, indicating the disruption of the bilayer curvature and leakages of cellular cytoplasmic contents. The antibacterial peptides are divided into membrane disruption and non-membrane disruption mechanism classes, depending on whether the reorientation of peptide leads to perturbation of the integrity of the cell membrane or peptide translocation into the cytoplasm [18,20]. From the result of SEM, it can be inferred that HAHp2-3-I could perform antibacterial activity via membrane disruption model.

In the membrane disruption mechanism, "barrel-stave", "carpet" or "toroidal-pore" mechanisms are well reported. In the "barrel-stave", or "toroidal-pore" model, it is required that the peptides span the lipid bilayer, whereas peptides with less than 20 residues are unable to span the lipid bilayer [28]. All identified peptides in HAHp2-3-I were less than 16 residues (seen in Table 1), and thus they seem unable to span the lipid bilayer through the "barrel-stave", or "toroidal-pore" model. However, it should be mentioned that some $\alpha$-helical peptides with as few as 13 residues are reported to possess antibacterial activity, so the ability to span a lipid bilayer is not a prerequisite for the antibacterial activity of peptides with $\alpha$-helices [27]. In the case of the "carpet" model, antibacterial peptides with net charges will be attached to the membrane surface by electrostatic effects, and then accumulate on the bilayer surface like a carpet. Finally, the bilayer is disrupted in a detergent-like manner, and micelles are usually observed on the membrane surface [20,29,30]. In our present study, micelles and pores on the surface of $E$. coli after incubation with HAHp2-3-I were clearly observed (Figure 5b,c). In combination the physicochemical properties and prediction of peptides secondary structure (see Tables 1 and 2) with the result of SEM, we presume that the antibacterial mechanism of HAHp2-3-I is more likely the "carpet" model. While recognition of the antibacterial mechanism of bioactive peptides is complicated and no single technique is sufficient to explain the action, the present study may, at 
least, provide necessary information for preparation and identification of antibacterial peptide fractions from fish hydrolysates, yet further investigations need to be done.

Figure 5. Scanning electron microscopy of Escherichia coli treated with HAHp2-3-I. (a) Control, absence of HAHp2-3-I; (b), (c) treatments, presence of HAHp2-3-I. Bars in figure represented $5 \mu \mathrm{m}$. Micelles, pores, and membrane disruption were marked with arrows.

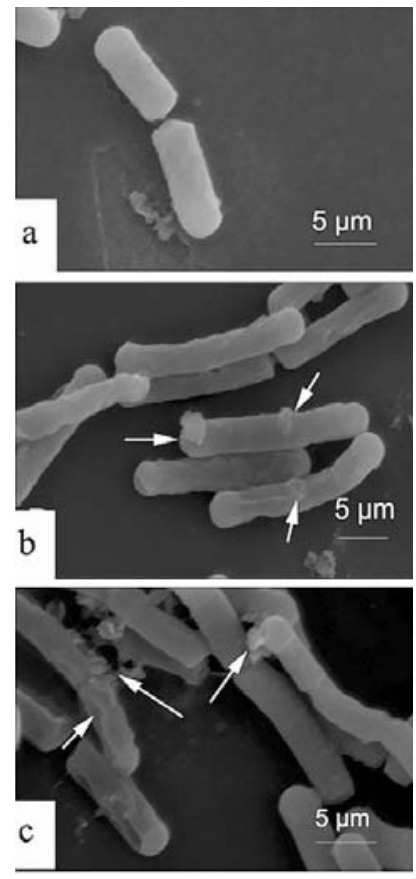

\section{Experimental}

\subsection{Materials}

The half-fin anchovy (Setipinna taty) marine fish were purchased from a local fish market in Zhoushan, China. Pepsin was provided by Sinopharm Chemical Reagent Co. Ltd (Shanghai, China). Agar, peptone and beef extract were purchased from Tianhe Microbial-agent Co. Ltd (Hangzhou, China). Escherichia coli strain was provided by College of Food Science and Pharmacy, Zhejiang Ocean University. Elute solutions used in the experiments were of chromatographic grade for HPLC and UPLC. Other reagents were analytical grade and commercially available.

\subsection{Preparation of the Pepsin Hydrolysate of Half-Fin Anchovy (HAHp)}

The pepsin hydrolysate of half-fin anchovy was prepared according to the optimized method described in our previous study [17]. Briefly, ground fish muscle was mixed with deionized water at a ratio of $1: 4(\mathrm{w} / \mathrm{v})$. The $\mathrm{pH}$ of the mixture was adjusted to 2.0 with $6 \mathrm{~mol} / \mathrm{L} \mathrm{HCl}$. Pepsin was added to the mixture at a ratio of $1100 \mathrm{U} / \mathrm{g}$. The hydrolysis was performed at $37{ }^{\circ} \mathrm{C}$ for $2.4 \mathrm{~h}$, terminated by heating at $95{ }^{\circ} \mathrm{C}$ for $10 \mathrm{~min}$. Then the $\mathrm{pH}$ of the hydrolysates was adjusted to 7.0 and centrifuged at $10,000 \times g$ for $20 \mathrm{~min}\left(4^{\circ} \mathrm{C}\right)$ to remove the insoluble material. The soluble hydrolysate was named as HAHp. The hydrolysis degree (DH) and soluble peptides of HAHp were $(18.12 \pm 0.39) \%$ and $(81.78 \pm 0.04) \%$, respectively, measured by the method described in Song et al. [31]. 


\subsection{Antibacterial Activity against Escherichia coli}

The agar-well diffusion method [32] with further modifications was used to determine the antibacterial activity of fractions isolated from HAHp. E. coli was the most susceptible bacterial strain to HAHp [17], therefore, in this study, E. coli was used as the indicator stain. E. coli suspension (100 $\mu \mathrm{L})$ grown in a nutrient broth $\left(18-24 \mathrm{~h}\right.$ old, approx. $\left.10^{8}-10^{9} \mathrm{CFU} / \mathrm{mL}\right)$ was pipetted into a Petri dish, then $15 \mathrm{~mL}$ of nutrient agar $\left(45-50^{\circ} \mathrm{C}\right)$ was poured in to blend with the suspension. A sterilized steel punch was used to obtain wells ( $4 \mathrm{~mm}$ diameter) after the agar coagulated. Finally, $25 \mu \mathrm{L}$ of sample was added to each well and incubated at $37{ }^{\circ} \mathrm{C}$ for $24 \mathrm{~h}$. The formation of inhibition zone around the well was observed.

\subsection{Isolation of Antibacterial Fraction from $\mathrm{HAHp}$}

HAHp was fractioned on a Sephadex G-25 column $(26 \times 100$ mm; Amersham Pharmacia, Uppsala, Sweden) using an ÄKTA purifier system. To avoid absorption to the gel for ingredients with net charges or hydrophobic characteristics, we used $50 \mathrm{mM}$ sodium phosphate buffer $(\mathrm{pH} 5.8)$ in $0.15 \mathrm{~mol} / \mathrm{L} \mathrm{NaCl}$ as the eluent for the first round of separation on the Sephadex G-25 column. The flow rate was $1.0 \mathrm{~mL} / \mathrm{min}$. Peak fractions were pooled and lyophilized. The fraction with antibacterial activity against $E$. coli was subject to a second chromatographic step on the Sephadex G-25 column at a flow rate of $0.5 \mathrm{~mL} / \mathrm{min}$, eluted with deionized water. The chromatographic profile was measured at $215 \mathrm{~nm}$, which indicates the absorbance of peptide bonds. The bioactive peak fraction was dissolved in $5 \%$ acetonitrile containing $0.1 \%(\mathrm{v} / \mathrm{v})$ TFA (solvent $\mathrm{A}$ ), and then applied to a $\mathrm{C}_{18}$ preparative reversed-phase column $(10 \times 250 \mathrm{~mm}, 10 \mu \mathrm{m})\left(\right.$ Sunfire $^{\mathrm{TM}}$, Waters, Milford. MA, USA). Solvent B was $0.1 \%(\mathrm{v} / \mathrm{v}) \mathrm{TFA}$ in $95 \%$ acetonitrile. The separation was performed using a linear gradient from $15 \%$ to $45 \% \mathrm{~B}$ in $40 \mathrm{~min}$ at a flow rate of $2.0 \mathrm{~mL} / \mathrm{min}$, measured at $215 \mathrm{~nm}$. The bioactive peak was further purified, using a Source 5RPC ST column $(4.6 \times 150 \mathrm{~mm}, 5 \mu \mathrm{m})$ (Amersham Pharmacia) in a gradient elution from $12 \%$ to $16 \%$ of $0.1 \%(\mathrm{v} / \mathrm{v})$ TFA in acetonitrile in $14 \mathrm{~min}$, and measured at $215 \mathrm{~nm}$ with a flow rate of $0.5 \mathrm{~mL} / \mathrm{min}$.

\subsection{Peptide Sequence Analysis and Physicochemical Properties}

The lyophilized antibacterial fraction from $\mathrm{C}_{18}$ RP-HPLC was purified by employing an UPLC Michrom $\mathrm{C}_{18}$ reverse phase column $(0.1 \times 150 \mathrm{~mm}, 200 \AA$, Waters $)$ with the same buffer conditions as $\mathrm{C}_{18}$ RP-HPLC. The elution was carried out at a flow rate of $300 \mathrm{~nL} / \mathrm{min}$, with $5 \%$ solvent $\mathrm{B}$ for $5 \mathrm{~min}$, $5 \%$ to $8 \%$ solvent B for $7 \mathrm{~min}, 8 \%$ to $13 \%$ solvent B for $10 \mathrm{~min}$ and $13 \%$ to $30 \%$ solvent $\mathrm{B}$ for $20 \mathrm{~min}$. The separated peaks were analyzed by a LTQ-Orbitrap mass spectrometer (Thermo, Waltham, MA, USA) under ESI positive ionization mode $\left(+2.5 \mathrm{Kv}\right.$ ionspray voltage, $200{ }^{\circ} \mathrm{C}$ capillary temperature), scanning from a mass-to-charge ratio $(\mathrm{m} / \mathrm{z})$ of $400-1,800$. Amino acid sequences of peptides were automatically determined by 'de novo' sequence software. The physicochemical properties of peptides were predicted using web-based peptide sequence analysis tools, Expert Protein Analysis System (ExPASy) (ProtParam, http://us.expasy.org/tools/protparam.html) [33,34] and antimicrobial peptide database (APD http://aps.unmc.edu/AP/main.php). 


\subsection{Prediction of the Secondary Structure of Peptide}

The secondary structures of the identified peptides were predicted by the protein sequence analysis tool of Hierarchical Neural Network in NPS@ (Network Protein Sequence@nalysis).

\subsection{Scanning Electron Microscopy (SEM)}

Exponential phase cultures of $E$. coli cells $(18 \mathrm{~h}$ old) were incubated with the antibacterial peptide fraction HAHp2-3-I $(60 \mu \mathrm{g} / \mathrm{mL})$ at $37{ }^{\circ} \mathrm{C}$ for $20 \mathrm{~h}$. After centrifugation for $10 \mathrm{~min}$ at $2000 \times \mathrm{g}\left(4^{\circ} \mathrm{C}\right)$, the resulting pellet was washed twice with sterile saline water, and then re-suspended in $3.0 \%$ glutaraldehyde for $12 \mathrm{~h}$ at ambient temperature. Subsequently, the solution was rinsed three times with $10 \mathrm{mM}$ sodium phosphate buffer (pH 7.0), and dehydrated in a graded series of ethanol solutions. After critical-point drying and layering with $20 \mathrm{~nm}$ gold coating, the microscopy was performed with an S-3400N scanning electron microscope (Hitachi, Tokyo, Japan). Cell suspension of E. coli without the addition of HAHp2-3-I was treated as the control.

\section{Conclusions}

The pepsin hydrolysate of the marine fish half-fin anchovy contained antibacterial peptide fractions. HAHp2-3-I, an antibacterial peptide fraction whose molecular weight ranges from 1,100 to 1,700 Da was isolated and characterized. Peptides sequences prediction showed that HAHp2-3-I contained net charged peptides, which could form extended strands, random coils and alpha helix structures. HAHp2-3-I might exert its antibacterial activity via a membrane disruptive model in the "carpet" model way. In sum, the results of this study may provide useful information for investigation of antibacterial peptides derived from fish hydrolysates.

\section{Acknowledgments}

This study was supported by the grants from Education Department of Zhejiang Province, China (Y200909275), the Natural Science Foundation of Zhejiang Province (Y3110153), and the Natural Science Foundation of China (31071628).

\section{References and Notes}

1. Steiner, H.; Hultmark, D.; Engström, Å.; Bennich, H.; Boman, H.G. Sequence and specificity of two antibacterial proteins involved in insect immunity. Nature 1981, 292, 246-248.

2. Broekaert, W.F.; Terras, F.R.; Cammue, B.P.; Osborn, R.W. Plant defensins: Novel antimicrobial peptides as components of the host defense system. Plant Physiol. 1995, 108, 1353-1358.

3. Mkrtchyan, H.; Gibbons, S.; Heidelberger, S.; Zloh, M.; Limaki, H.K. Purification, characterisation and identification of acidocin LCHV, an antimicrobial peptide produced by Lactobacillus acidophilus n.v. Er 317/402 strain Narine. Int. J. Antimicrob. Agents 2010, 35, 255-260.

4. Rajanbabu, V.; Chen, J.Y. Applications of antimicrobial peptides from fish and perspectives for the future. Peptides 2011, 32, 415-420. 
5. Hill, R.D.; Lahav, E.; Givol, D. A rennin-sensitive bond in alpha-s1 B-casein. J. Dairy Res. 1974, $41,147-153$.

6. Jones, F.S.; Simms, H.S. The bacterial growth inhibitor (lactenin) of milk. J. Exp. Med. 1930, 51, 327-339.

7. Zucht, H.D.; Raida, M.; Adermann, K.; Mägert, H.J.; Forssmann, W.G. Casocidin-I: A casein- $\alpha_{\mathrm{s} 2}$ derived peptide exhibits antibacterial activity. FEBS Lett. 1995, 372, 185-188.

8. Liu, Z.Y.; Dong, S.Y.; Xu, J.; Zeng, M.Y.; Song, H.X.; Zhao, Y.H. Production of cysteine-rich antimicrobial peptide by digestion of oyster (Crassostrea gigas) with alcalase and bromelin. Food Control 2008, 19, 231-235.

9. Mine, Y.; Ma, F.P.; Lauriau, S. Antimicrobial peptides released by enzymatic hydrolysis of hen egg white lysozyme. J. Agric. Food Chem. 2004, 52, 1088-1094.

10. Pellegrini, A.; Hülsmeier, A.J.; Hunziker, P.; Thomas, U. Proteolytic fragments of ovalbumin display antimicrobial activity. Biochim. Biophys. Acta 2004, 1672, 76-85.

11. Bolscher, J.G.M.; van der Kraan, M.I.A.; Nazmi, K.; Kalay, H.; Grün, C.H.; van't Hof, W.; Veerman, E.C.I.; Nieuw Amerongen, A.V. A one-enzyme strategy to release an antimicrobial peptide from the LFampin-domain of bovine lactoferrin. Peptides 2006, 27, 1-9.

12. Subramanian, S.; Ross, N.W.; Mackinnon, S.L. Comparison of the biochemical composition of normale pidermal mucus and extruded slime of hagfish (Myxine glutinosa L.). Fish Shellfish Immunol. 2008, 25, 625-632.

13. Noga, E.J.; Ullal, A.J.; Corrales, J.; Fernandes, J.M. Application of antimicrobial polypeptide host defenses to aquaculture: Exploitation of downregulation and upregulation responses. Comp. Biochem. Physiol. D 2011, 6, 44-45.

14. Chen, S.L.; Xu, M.Y.; Ji, X.S.; Yu, G.C.; Liu, Y. Cloning, characterization, and expression analysis of hepcidin gene from red sea bream (Chrysophrys major). Antimicrob. Agents Chemother. 2005, 49, 1608-1612.

15. Dong, X.Z.; Xu, H.B.; Huang, K.X.; Liou, Q.; Zhou, J. The preparation and characterization of an antimicrobial polypeptide from the loach, Misgurnus anguillicaudatus. Protein Expr. Purif. 2002, $26,235-242$.

16. Hirono, I.; Hwang, J.Y.; Ono, Y.; Kurobe, T.; Ohira, T.; Nozaki, R.; Aoki, T. Two different types of hepcidins from the Japanese flounder Paralichthys olivaceus. FEBS J. 2005, 272, 5257-5264.

17. Song, R.; Wei, R.B.; Zhang, B.; Wang, D.F. Optimization of the antibacterial activity of half-fin anchovy (Setipinna taty) hydrolysates. Food Bioprocess Technol. 2011, doi:10.1007/s11947-010-0505-3.

18. Friedrich, C.L.; Moyles, D.; Beveridge, T.J.; Hancock, R.E.W. Antibacterial action of structurally diverse cationic peptides on Gram-positive bacteria. Antimicrob. Agents Chemother. 2000, 44, 2086-2092.

19. Mandal, S.M.; Dey, S.; Mandal, M.; Sarkar, S.; Maria-Neto, S.; Franco, O.L. Identification and structural insights of three novel antimicrobial peptides isolated from green coconut water. Peptides 2009, 30, 633-637.

20. Pouny, Y.; Rapaport, D.; Mor, A.; Nicolas, P.; Shai, Y. Interaction of antimicrobial dermaseptin and its fluorescently labeled analogues with phospholipid membranes. Biochemistry 1992, 31, $12416-12423$. 
21. Kustanovich, I.; Shalev, D.E.; Mikhlin, M.; Gaidukov, L.; Mor, A. Structural requirements for potent versus selective cytotoxicity for antimicrobial dermaseptin S4 derivatives. J. Biol. Chem. 2002, 277, 16941-16945.

22. Zelezetsky, I.; Pag, U.; Sahl, H.G.; Tossi, A. Tuning the biological properties of amphipathic alpha-helical antimicrobial peptides: rational use of minimal amino acid substitutions. Peptides 2005, 26, 2368-2376.

23. Bello, J.; Bello, H.R.; Granados, E. Conformation and aggregation of melittin: Dependence on $\mathrm{pH}$ and concentration. Biochemistry 1982, 21, 461-465.

24. Falla, T.J.; Karunaratne, D.N.; Hancock, R.E.W. Mode of action of the antimicrobial peptide indolicidin. J. Biol. Chem. 1996, 271, 19298-19303.

25. Gennaro, R.; Zanetti, M. Structural features and biological activities of the cathelicidin-derived antimicrobial peptides. Biopolymers 2000, 55, 31-49.

26. Park, C.B.; Yi, K.S.; Matsuzaki, K.; Kim, M.S.; Kim, S.C. Structure-activity analysis of buforin II, a histone H2A derived antimicrobial peptide: the proline hinge is responsible for the cell-penetrating ability of buforin II. Proc. Natl. Acad. Sci. USA 2000, 97, 8245-8250.

27. Zhang, L.; Rozek, A.; Hancock, R.E.W. Interaction of cationic antimicrobial peptides with model membranes. J. Biol. Chem. 2001, 276, 35714-35722.

28. Zasloff, M.; Martin, B.; Chen, H.C. Antimicrobial activity of synthetic magainin peptides and several analogues. Proc. Natl. Acad. Sci. USA 1988, 85, 910-913.

29. Ladokhin, A.S.; White, S.H. 'Detergent-like' permeabilization of anionic lipid vesicles by melittin. Biochim. Biophys. Acta 2001, 1514, 253-260.

30. Shai, Y. Mechanism of the binding, insertion and destabilization of phospholipid bilayer membranes by alphahelical antimicrobial and cell non-selective membrane-lytic peptides. Biochim. Biophys. Acta 1999, 1462, 55-70.

31. Song, R.; Wei, R.B.; Zhang, B.; Yang, Z.S.; Wang, D.F. Antioxidant and antiproliferative activities of heated sterilized pepsin hydrolysate derived from half-fin anchovy (Setipinna taty). Mar. Drugs 2011, 9, 1142-1156.

32. Murthy, P.S.; Manonmani, H.K. Physico-chemical, antioxidant and antimicrobial properties of Indian monsooned coffee. Eur. Food Res. Technol. 2009, 229, 645-650.

33. Gasteiger, E.; Gattiker, A.; Hoogland, C.; Ivanyi, I.; Appel, R.D.; Bairoch, A. ExPASy: The proteomics server for in-depth protein knowledge and analysis. Nucleic. Acids Res. 2003, 31, 3784-3788.

34. Gasteiger, E.; Hoogland, C.; Gattiker, A.; Duvaud, S.; Wilkins, M.R.; Appel, R.D.; Bairoch, A. Protein Identification and Analysis Tools on the ExPASy Server. In The Proteomics Protocols Handbook; Walker, J.M., Ed.; Humana Press Inc.: Totowa, NJ, USA, 2005; pp. 571-607.

Sample Availability: Contact the authors.

(C) 2012 by the authors; licensee MDPI, Basel, Switzerland. This article is an open access article distributed under the terms and conditions of the Creative Commons Attribution license (http://creativecommons.org/licenses/by/3.0/). 